\title{
Basic Assumptions of Service Employees: Influence on Job Performance and Market-oriented Behaviors
}

\author{
Olga Gjerald (Corresponding author) \\ Associate Professor, University of Stavanger, Ullanhaug, 4036 Stavanger, Norway \\ Tel: 47-5183-3763 / 47-5183-3750_E-mail: olga.gjerald@uis.no \\ Torvald Øgaard \\ Professor, University of Stavanger, Ullanhaug, 4036 Stavanger, Norway \\ E-mail: torvald.ogaard@uis.no
}

Received: August 23, $2012 \quad$ Accepted: September 13, $2012 \quad$ Online Published: October 26, 2012

doi:10.5430/ijba.v3n6p1 URL: http://dx.doi.org/10.5430/ijba.v3n6p1

\begin{abstract}
Understanding what drives frontline service employees in their interactions with guests and customers is a focal question in service management. Employees' basic assumptions may determine employee performance and work behavior in several domains. This study investigates the relation of service employees' basic assumptions about customers and co-workers with subjective job performance and market-oriented behaviors of service employees. The study sample consists of 241 hotel employees. The analyses revealed that basic assumption about co-worker competence associated positively with customer intelligence generation, intelligence dissemination, and responsiveness. The basic assumption about customer control related positively with perceived customer-related performance but negatively with customer intelligence generation and responsiveness. The results of the study suggest that basic assumptions about co-workers can predict customer-related behavior; therefore, researchers should consider that the basic assumptions about customers significantly influence job performance towards customers.
\end{abstract}

Keywords: Basic assumptions, Market orientation, Job performance, Service management, Implicit theories, Social cognition

\section{Introduction}

Customers' satisfaction with services and service quality often depends on the service employees' personal performance when interacting with the customers (Hartline and Ferrell, 1996). Understanding what drives frontline service employees in their performance with customers is a focal question in service management, and researchers have conceptualized and analyzed the problem using a number of different theoretical approaches, for example employee empowerment (Lashley, 2001), employee involvement (Baker, Cronin, and Hopkins, 2009), employee self-efficacy (Hartline and Ferrell, 1996), and employee knowledge sharing (Reychav and Weisberg, 2009).

People's basic assumptions about the way the world works may be an important construct for understanding human behavior (Hochwälder, 1995; Lord and Maher, 1993). Basic assumptions include knowledge structures that exist in long-term memory, guide information processing in several domains, generate behavior, form social perceptions, and guide social interactions (Lord and Maher, 1993). The ability to identify and help others discover their basic assumptions, and the capability to challenge those assumptions if necessary, is possibly the most critical capability a human resource manager can possess (Pfeffer, 2005). Psychology (Janoff-Bulman, 1989), social psychology (Lord and Brown, 2001), sociology (Moscovici, 2000), and anthropology (Kluckhohn, 1951) fields made significant contributions to the literature on basic assumptions.

Concerning work life, basic assumptions are defined as a socially constructed understanding of the world (or its particular parts) derived from social exchanges and interactions among multiple individuals in a group or organization (cf. Lord and Emrich, 2000). In service interactions, customization is quite often a goal in itself. Serving heterogeneous customers with varying needs and wants requires more than just following rote behavior, roles, rules, and scripts on the part of employees. If the service employee can no longer rely on the guidance of rules and scripts, 
basic assumptions may form a backdrop that allows the employees to improvise their behavior. Basic assumptions thus may be of particular relevance for understanding the performance of the service worker. In the literature, high-contact service work has often been described as "emotional labour" (Hochschild, 1983), "performative work" (Bærenholdt and Jensen, 2009), or working "under the gaze" of consumers (Urry, 1990). Employees' performance and behavior during customer interaction is especially crucial because for many, interaction is the service from the customer's point of view (Bitner, 1990).

Even though basic assumptions likely influence job outcomes of employees (Banse and Greenwald, 2007), a shortage of empirical studies exists on implicit assumptions and their relation to major focus areas of service management, such as employees' work outcomes and market orientation. Gjerald and Øgaard (2010a, 2010b) provided conceptual as well as empirical definitions of basic assumptions that allow for a more careful empirical investigation. The study here applies these new insights to investigate the relation between basic assumptions about customers and co-workers and service employees' job performance and market-oriented behaviors.

The paper has five parts. Following this introduction, Part 2 reviews the available literature on basic assumptions. Part 3 proposes a conceptual model. Part 4 presents the research method and discusses the data collection and analysis techniques. Part 5 discusses the findings and present some implications of the study.

\section{Theory}

The available literature defines basic assumptions as taken-for-granted perspectives of viewing the world that guide behavior (Lord and Maher, 1993; Schein, 2004). Basic assumptions are central to the mental life of individuals. Koltko (2000) suggested that basic assumptions about the reality are required for "any sort of human logic or rational processes to function." In his description of basic organizational assumptions, Schein (1985) proposed that basic assumptions are similar to Argyris' (1976) concept of "theories-in-use," which refers to the implicit theories that actually guide behavior and tell organizational members how to perceive, think about, and feel about things (Argyris, 1976; Argyris and Schön, 1974).

During the past four decades, studies have utilized several theories to study basic assumptions. Among these theories are (a) "implicit personality theory" (Heslin, Latham, and Vandewalle, 2005), which pertains to people's implicit assumptions about the types of personality attributes that tend to co-occur (e.g., conscientiousness and friendliness), (b) "implicit theories" (Wentzel, Henkel, and Tomszak, 2010), which studies two distinct types of implicit person theories or assumptions about people - entity and incremental implicit theories, (c) "implicit leadership theories" (Lord and Brown, 2004), which deal with assumptions about the traits and abilities that characterize an ideal business leader, and (d) "social representation theory" (Moscovici, 2000), which addresses formation and functioning of social representations, that is, cognitive systems, which people use to organize information about the social world.

Existing conceptualizations of basic assumptions can be divided into two broad, overlapping categories: assumptions about life in general and specific assumptions about work life. Assumptions about life in general are studied in general social sciences like applied psychology (e.g., Berzonsky, 1994) or anthropology (e.g., Lawler, Walumbwa, and Bai, 2008). Previous literature identifies the dimensions of basic assumptions in relation to human nature, will, behavior, interpersonal relations, and the world in general. For example, Koltko-Rivera (2000) conceptualized a person's assumptions as a six-dimensional construct involving mutability, agency, relation to authority, relation to group, locus of responsibility, and metaphysics. Mutability refers to the possibility of changing human nature. Agency is the degree to which behavior is chosen or determined. Relation to authority identifies hierarchical versus egalitarian partnerships. Relation to group assesses priority given to individual goals versus reference group goals. Locus of responsibility describes perceived responsibility for the person's situation in life. Lastly, Metaphysics refers to the reality or unreality of a spiritual dimension in life.

Work-related assumptions are the products of socialization into an organizational or a professional culture; consequently, they have been of interest to, for example, human resources management (Deadrick and Gibson, 2009), leadership (Epitropaki and Martin, 2004), and organizational culture (Schein, 2005). Most attempts to assess work-related assumptions have departed from assumptions about life in general, and they have been adapted to the organizational context (e.g., Mikkelsen and Einarsen, 2002). For instance, Schein (2004) developed five categories of basic assumptions as a framework for organizational purposes. (1) Human nature involves assumptions that define the meaning of being human and human attributes that are considered intrinsic and ultimate. (2) Nature of human activity involves assumptions about the appropriate level of activity or passivity. (3) Nature of human relationship involves assumptions about the right way for people to relate to each other and distribute power. (4) Nature of time and space concerns assumptions about the appropriate focus of one's activities, future, present, or past, and about the allocation and ownership of the space. (5) Nature of reality and truth concerns assumptions that define what is real 
and what is not, assumptions about how truth is ultimately determined, and assumptions about whether truth is revealed or discovered.

Two basic assumptions seem to be of particular importance to service interaction management: assumptions about customers and assumptions about co-workers (Gjerald and Øgaard, 2008). They relate to the human nature, nature of human activity, and nature of human relationships (cf. Schein, 2004), and they are considered to be of particular importance to services since they relate to the most important elements of interactions, that is, customers and colleagues involved in the interaction production.

Basic assumption about customer control refers to a general belief that customer-employee interaction outcomes are contingent upon employees' own efforts and actions. Employees with strong customer control assumption believe in increasing predictability of the interaction, gaining control over customer interaction, and emphasizing standards and rules in their service production.

Basic assumption about customer affect refers to a general belief that emotional exposure to customers is a part of service creation and delivery. Employees with strong customer affect assumption believe that emotional aspects of their work (e.g. emotional display, affective customer attachment) are natural to service creation and delivery.

Basic assumption about co-workers' competence refers to a general belief that service delivery outcomes are contingent upon co-worker competence. Employees with strong co-worker competence assumptions believe that co-workers' knowledge, task-solving efficiency, communication style, and the ability to evolve and improvise are of vital importance to service creation and delivery.

Basic assumption about co-worker responsibility refers to a general belief that service co-workers have inherent responsibility over service production. Employees with strong co-worker responsibility assumption believe that co-workers' self-reliance, accountability, and independence are crucial to service creation and delivery.

If basic assumptions are important for employee behavior during interactions, the assumptions should relate to service outcomes. In competitive service environments, the general focus is on performance outcomes that can lead to long-term organizational success (Ingram, 1997). Although "bottom line" performance measurement is important, "softer" indicators, for example attitudinal measures of employee perceptions and outcomes, may offer greater opportunities for influencing long-term organizational effectiveness (Ingram, 1997). For this study, subjective performance evaluation was chosen from among attitudinal measures of individual outcomes, which have been well documented to relate to actual performance (e.g., Harris and Mossholder, 1996). Subjective performance evaluations (i.e., employees' self-assessments of performance) have been systematically related to actual performance (e.g., Van der Heijden, 2001). This study proposes that basic assumptions about co-workers and customers relate to subjective performance evaluations.

Since basic assumptions of employees are assumed to be important drivers of employee behavior (Lord and Brown, 2004), basic assumptions about customers and co-workers should relate to market orientation defined as a set of behaviors directed at customers and co-workers (Kaur and Gupta, 2010). Market orientation has been suggested as a critical antecedent of service firms' success (Jaworski and Kohli, 1993). Three types of employee behavior, that is, knowledge of present and future customer needs (customer intelligence generation), the dissemination of the acquired knowledge to other co-workers (intelligence dissemination), and the response provided to the customer based on the acquired knowledge (intelligence responsiveness), identify a market orientation (Kohli, Jaworski, and Kumar, 1993). In service companies, customer needs, customer expectations, and customer behaviors are constantly changing, driving companies to continuously monitor their markets and the business environment (Silva, Moutinho, Coelho, and Marques, 2009). Market-oriented companies should develop an internal, customer-oriented culture, as well as improve employee skills to produce creative solutions to market demands. Few studies have investigated the relationship between implicit knowledge structures about customers or co-workers and individual-level perceptions of market orientation activities. We suggest a reciprocal relationship between the employees' market orientation and basic assumptions, that is, between the basic assumptions of employees about both customers and co-workers and employees behavior toward customers and co-workers (intelligence generation and response to customers on one hand, and intelligence dissemination between co-workers on the other), if a market orientation is integrated in the company. Based on the above discussion, this study introduces a conceptual model illustrated in Figure 1.

The model guided the formulation of two sets of hypotheses. The first set consists of hypothesis regarding the relationships between the four different dimensions of basic assumptions and employee job performance (H1). The second set contains hypotheses regarding the relationships between the four dimensions of basic assumptions and three types of market-oriented behavior $(\mathrm{H} 2)$. The overview of the hypotheses is presented in Table 1. 


\section{Methods}

\subsection{Participants and Procedures}

Since the primary aim of the study is to test a theory, the data were collected from a single industry to reduce the error and increase power. We chose hotel as our sample industry because hotel services involve considerable contact with both customers and co-workers. Also, less homogenous industry would secure a reasonable amount of variance in the focal variables. The hospitality industry seemed particularly well suited. The basic operation of hotels is similar; however, individual hotels face quite different customer groups, different markets and competition, and different labor markets, and they have quite distinct histories that allow different basic assumptions to develop. To maximize the variance in the sample, this study includes a wide spectrum of hotel operations, hotels of different chains and different concepts within chains from small (three employees) to relatively large units (30 employees), city as well as remotely located hotels, business and convention venues as well as leisure market operators.

An invitation was sent out to general managers of 183 hotels and resorts belonging to 7 major hotel chains in Norway. After two follow-up waves, 40 managers agreed to participate and distribute the questionnaire to the employees. Two versions of the questionnaire were developed, one electronic and one pen-and-paper. Overall, 35 managers chose the electronic version and 5 chose the pen-and-paper version. The final sample consisted of 241 hotel employees. A description of the sample is included in the results section.

\subsection{Measures}

The electronic and pen-and-paper versions of the questionnaire were identical (except for the format). All items were measured on a 7-point Likert scale ranging from 1 (very poor description) to 7 (very good description).

Basic assumptions. An assessment instrument developed by Gjerald and Øgaard (2010b) measured basic assumptions about customers and co-workers. This study utilized 31-item instrument covering four dimensions of basic assumptions. The two dimensions of basic assumptions about customers were measured by 11 items evaluating basic assumption about customer control (e.g., "In this organization, we sometimes give less priority to the flexibility of products offered to achieve more control over the service interaction"), and 6 items evaluating basic assumption about customer affect (e.g., "Putting your emotions on display makes you feel closer to the guest"). The two dimensions of basic assumptions about co-workers were measured by 5 items evaluating basic assumption about co-worker responsibility (e.g., "A good co-worker is someone who acknowledges his/her responsibility to their colleagues"), and 9 items evaluating basic assumption about co-worker competence (e.g., "A competent co-worker knows his/her job better than a "training manual").

Subjective job performance was measured with two items adapted from Singh, Verbeke, and Rhoads (1996). Each employee had to evaluate him- or herself in comparison to co-workers and to hospitality industry employees in general (e.g., "Compared to others employees in this hotel I do an excellent job toward the guests").

Market orientation was measured by Jaworski and Kohli's (Kohli et al., 1993) Market Orientation instrument. The measure contains 32 items covering three dimensions of market-oriented activities: 10 items represent intelligence generation (e.g., "In this hotel, we meet guests at least once a year to find out what products or services they will need in the future"), 8 items represent information dissemination (e.g., "Data on guest satisfaction are disseminated at all levels in this hotel on a regular basis"), and 14 items capture information responsiveness (e.g., "For one reason or another, we tend to ignore changes in our guests' product or service needs"). Minor word revisions were applied to the original scales to ensure that the items were applicable to the hotel context (e.g., "guests" instead of "customers", "hotel" instead of "business unit").

\subsection{Data Analysis Strategy}

The data analyses were performed with SPSS 15.0 for Windows (SPSS, 2006). After assessing the sample characteristics, the measurement properties of the constructs, that is, the reliability and convergent- and discriminant validity of the measures, were established by evaluating Cronbach's alphas and the results of the factor analysis (Churchill, 1979). The hypotheses were tested with regression analysis.

\section{Results}

\subsection{Sample Characteristics}

The final sample consisted of 241 hotel employees. A closer analysis suggested that the sample comprises rather heterogeneous set of employees. The respondent's mean age was 32.3 years $(S D=9.3)$ with age ranging from 18 to 65 years old. In terms of gender, 62 percent were women and 38 percent were men. On an average, they had worked for their current employer for 4.7 years $(S D=4.7)$ and reported an average of 9.8 years $(S D=6.5)$ of work experience in 
the tourism and hospitality industry. Overall, 84 percent of the respondents reported that they held full-time positions. About 51 percent of the respondents were regular employees with no managerial functions while 35 percent were middle-level managers, and 14 percent were in top manager positions. In terms of their main occupation at work, 12 percent worked in sales, 6 percent in revenue and finance department, 10 percent in housekeeping, 7 percent in restaurant, 6 percent in kitchen, 42 percent in reception, 8 percent in convention and conference department, 5 percent in booking, and remaining 4 percent worked in ancillary services.

\subsection{Measurement Scale Validation}

First, the unidimensionality of each individual dimension of the basic assumptions measures was assessed with factor analyses of the items of each scale. The reliability of each scale was evaluated with Cronbach's alpha. In addition, range of communalities, range of factor loadings, and variance extracted by the first factor were inspected for all scales. The results are listed in Table 2.

Next, the convergent and discriminant (Churchill, 1979) validities of the basic assumptions measures were checked with a factor analysis that included all items from all scales. The results are displayed in Table 3. The results indicated that all basic assumption scales have adequate measurement properties for this kind of research. Cronbach's alpha values of the scales were above or close to the recommended value of .7 (Nunnally, 1978).

Similar analyses were performed on the dependent variables (market orientation and subjective job performance). The results presented in Table 2 indicate that all dependent measures have good measurement properties except for the intelligence generation dimension of market orientation, which had a less than desirable alpha value of .55. However, the measurement quality can be considered acceptable in this setting because the reliability of the intelligence generation dimension has been quite well documented in former studies (e.g., Morgan, Vorhies, and Mason, 2009) and the scale has been found fairly unidimensional. The results of the analyses above demonstrated the reliability and validity of the measurement scales. The composite scores (i.e., the means) were calculated for each scale. In addition to descriptive statistics presented in Table 2, Table 4 gives an overview over correlations among all scales included in the study.

4.3 Relationships between Basic Assumptions about Customers and Co-workers, Employee Job Performance, and Market-oriented Behaviors

The first set of hypothesis concerning the relationship between basic assumptions and subjective performance (H1) was evaluated with regression analysis. The dimensions of basic assumptions were entered into the equation simultaneously. The model reached statistical significance $(p<.05)$ and explained about $10 \%$ variance in the dependent variable (see Table 5). The second set of hypotheses concerning the relationships between basic assumptions and market-oriented behaviors of intelligence generation, intelligence dissemination, and responsiveness (H2) was tested with regression analysis (see Table 6).

First, the study investigated the influence of four basic assumption dimensions on intelligence generation (H2a1, $\mathrm{H} 2 \mathrm{~b} 1, \mathrm{H} 2 \mathrm{c} 1$, and $\mathrm{H} 2 \mathrm{~d} 1$ ). All four assumptions were entered simultaneously into the regression analysis. The model had a $\mathrm{R}^{2}$ of .10 and was significant at .001 level. Two basic assumption dimensions were significantly associated with intelligence generation: basic assumption about customer control and basic assumption about co-worker competence. Basic assumption about customer control demonstrated a negative association with intelligence generation, thereby confirming H2a1. Basic assumption about co-worker competence showed a positive association with intelligence generation, thereby confirming $\mathrm{H} 2 \mathrm{~d} 1$. The two remaining dimensions of basic assumptions did not show any significant relation with the dependent variable of intelligence generation.

Second, the relationships between the four basic assumption dimensions and intelligence dissemination were investigated (H2a2, H2b2, H2c2 and H2d2). The model had a $\mathrm{R}^{2}$ of 0.08 and was significant at the 0.005 level. Out of four independent variables in this model, one turned out to be a significant predictor of intelligence dissemination, that is, basic assumption about co-worker competence. Basic assumption about co-worker competence was positively associated with intelligence dissemination, thereby confirming $\mathrm{H} 2 \mathrm{~d} 2$.

Third, the relationship between the four basic assumptions and intelligence responsiveness was investigated (H2a3, $\mathrm{H} 2 \mathrm{~b} 3, \mathrm{H} 2 \mathrm{c} 3$, and $\mathrm{H} 2 \mathrm{~d} 3$ ). The model had a $\mathrm{R}^{2}$ of 0.17 and was significant at the 0.001 level. Three out of four basic assumptions showed significant relationship with the dependent variable. Both basic assumption about customer affect and basic assumption about co-worker competence were positively associated with responsiveness, thereby confirming $\mathrm{H} 2 \mathrm{~b} 3$ and $\mathrm{H} 2 \mathrm{~d} 3$. Basic assumption about customer control demonstrated a negative association with responsiveness, thereby confirming $\mathrm{H} 2 \mathrm{a} 3$. The following section provides the discussion of the results. 


\section{Discussion and Implications}

The results of the study showed that two out of four basic assumption dimensions related significantly to perceived customer related performance. Subjective job performance is a cognitive appraisal of own customer-related performance while basic assumptions are cognitive appraisals of the two important job components in the service co-creation, customers and co-workers. The findings showed that basic assumption about customer control and basic assumption about co-worker competence account for about $10 \%$ of variance in perceived customer-related performance. When controlled for the effects of market orientation activities, the effects of assumptions did not change significantly.

Basic assumption about customer control related positively to employees' customer-related performance. This partly contradicts and partly supports previous findings. Studies in the organizational culture field have shown that large amount of rules and regulations within organizations may negatively influence employee's job outcome (Philip and McKeown, 2004). At the same time, previous research on sales and marketing personnel has revealed that the focus on the task and strict regulations may actually be seen as a willingness of the employer to take the responsibility for the employee, which in turn positively affects employee job outcomes (Oliver and Anderson, 1995).

Basic assumption about co-worker competence also appears to have a positive effect on employee's customer-related performance. This finding can be explained by the nature of service work and service delivery. Production of services is a collective undertaking, a "performative work" (Bærenholdt and Jensen, 2009). As in any performance, co-workers play a vital part in delivering the product to consumers (Pine and Gilmore, 1999). While the responsibility assumption accentuates stability, responsibility towards colleagues, and the promotion of self-reliance, the competence assumption accentuates being flexible, taking the initiative, and looking for alternative solutions. The results are especially interesting because they suggest that flexibility in back-stage production of services (which is very much reliant on co-workers) may interact with or even occur simultaneously with increasing predictability and control over customer interaction (front-line production). Both have a positive association with perceived customer-related performance of service employees.

The results of the study also indicated that basic assumptions about customer control and co-worker competence have a significant effect on market-oriented behaviors (see Table 5). Market orientation comprises three sets of customer-related and co-worker related behaviors: intelligence generation (from customers to other employees), intelligence dissemination (from employee to other employees), and intelligence responsiveness (from employees to customers). Market orientation activities create a continuous flow of information and clues between customers and co-workers. Successful market orientation activities depend on the interaction and cooperation between customers and co-workers.

The results of the study show that three out of four basic assumptions are significantly associated with different market orientation behaviors. Intelligence generation correlated positively with basic assumption about co-worker competence and negatively with basic assumption about customer control. These findings confirm a positive association between employees' belief in importance of co-worker competence in terms of overall service production and market research behavior involving detecting shifts in the industry and changes in the business environment. On the other hand, employees who believe that they are solely in control of the customer-employee interaction outcomes care little about polling customers about the quality of the product and services the firm offers.

Another set of market-oriented behaviors, intelligence dissemination, was positively associated with basic assumption about co-worker competence. The results indicated that service employees who assume that co-worker competence is essential to service co-creation are also good at discussing customers' needs with co-workers from different departments, disseminating data on customer satisfaction, and alerting co-workers on important customer information.

Third set of market-oriented behaviors, intelligence responsiveness, was associated positively with basic assumption about co-worker competence and basic assumption about customer affect and negatively with basic assumption about customer control. These results suggest that service employees who believe that emotional aspects of service work are natural to their relationship with customers tend to be responsive towards customers' needs and wants. On the contrary, employees who believe that they control the outcomes of the service interaction respond badly to changes in customers' product or service wishes. In addition, employees who believe that co-worker competence is important for service production are proactive in their efforts to modify a product or a service and respond to the customers immediately. 
Among the dimensions of basic assumptions employed in this study, only basic assumption about co-worker competence was associated with both customer-related and co-worker-related behavior. Service employees who believe that co-worker competence is essential for service co-creation and delivery seem engage in all three sets of market-oriented behaviors: gathering information from and about customers, disseminating this knowledge across the organization, and responding to the customers' changing needs. Previous research on market orientation has criticized the construct of market orientation for not taking into account internal market, that is, own employees (George, 1990). This request emphasizes the need for service managers to achieve effective internal exchanges within the organization and between the organization and its employees, which are a pre-requisite for successful exchanges with external markets (Kaur and Gupta, 2010). The results of our study suggest that basic assumptions about co-workers, in addition to customer or competitor orientation, may be an important antecedent of such internal market orientation.

Two other dimensions of basic assumptions, which have produced significant correlations with market-oriented behaviors, were associated with generation of and responsiveness to customer-related intelligence. Service employees who believe in having control over interaction with customers seem to do little customer intelligence. Moreover, customer control assumption correlated negatively with responsiveness to customer intelligence. On the other hand, employees who assume emotions as a natural part of service work seem to be able to manage intelligence responsiveness. In terms of a service-dominant logic for marketing (Vargo and Lusch, 2004), a belief in control over customers may be seen as a belief in control over the process of service value co-creation (Gronroos, 2008). In this sense, customers may not be considered full co-producers of service but only receivers of a "pre-packed" product. Such a product-dominant logic emphasizes the needs of the service producer rather than the needs of consumers (Vargo and Lusch, 2008). Overall, based on the results of the study, we argue that basic assumption about customer control may be seen as an antecedent of a product-dominant logic, as it places the emphasis on controlling the service production and relates negatively to customer intelligence generation and responsiveness to consumers.

It is also interesting to notice that basic assumption about co-worker responsibility did not yield any significant results in the current study. On the other hand, basic assumption about co-worker competence demonstrated significant relationships with all outcome variables. Although these two assumptions should not be seen as complete opposites, they accentuate different orientations. While basic assumptions about co-worker responsibility can be associated with stability, basic assumptions about co-worker competence can involve flexibility. In the current sample, a belief in flexibility of operations turned out to be more significant for service employees' performance than a belief in stability of operations.

Our results suggest that by acquiring knowledge about the content and influence of service employees' basic assumptions, marketing managers may develop a better understanding of the internal market (i.e., own employees) and thereby contribute to the success of their organizations. Enacting market-oriented behaviors represents a challenge to the organization. Adopting market orientation requires a committed effort by the organization (i.e., employees) to identify the wants and needs of customers and to use this information to create offers that will add value for customers.

The results of the study demonstrated that a basic assumption about customer control was negatively associated with generation of customer intelligence. A practical implication of this finding may relate to motivation of service employees. Obtaining more information about a complex problem (e.g., customer intelligence) or detailed instructions on how to deal with an issue without having a certain mental model or implicit assumption to interpret the information will not necessarily help a person solve the problem. By helping employees understand their own implicit assumptions, a leader can increase their ability to learn and solve problems. This way, service managers can also help employees understand that they are powerful agents of change and can collectively influence events in the organization.

One limitation of this study is that more than just four dimensions of basic assumptions about customer and co-workers discussed herein can influence employees' perceived customer-related performance and market-oriented behaviors. Furthermore, this study associated basic assumptions about customers and co-workers only with self-evaluated individual employee outcomes. Future research should examine other performance measures, such as, aggregated performance or customer outcomes. The present study examined the relationships between cognitive appraisals of service employees (basic assumptions and self-rated performance). Future research efforts should also be directed towards investigating the relationships of basic assumptions about customers and coworkers with other types of manifest behavior in service employees. 


\section{References}

Argyris, C. (1976). Increasing leadership effectiveness. New York: Wiley-Interscience.

Argyris, C., \& Schön, D. A. (1974). Theory in practice: Increasing professional effectiveness. San Francisco: Jossey-Bass.

Bærenholdt, J. O., \& Jensen, H. L. (2009). Performative work in tourism. Scandinavian Journal of Hospitality and Tourism, 9(4), 349-365.

Baker, T. L., Cronin, J. J., \& Hopkins, C. D. (2009). The impact of involvement on key service relationships. Journal of Services Marketing, 23(2-3), 115-124. http://dx.doi.org/10.1108/08876040910946378

Banse, R., \& Greenwald, A. G. (2007). Personality and implicit social cognition research: Past, present and future. European Journal of Personality, 21(3), 371-382.

Bitner, M. J. (1990, April). Evaluating service encounters: the effects of physical surroundings and employee responses. Journal of Marketing 54, 69-82.

Churchill, G. A. (1979). A Paradigm for Developing Better Measures of Marketing Constructs. Journal of Marketing Research, 16(1), 64-73.

Deadrick, D. L., \& Gibson, P. A. (2009). Revisiting the research-practice gap in HR: A longitudinal analysis. Human Resource Management Review. [Online] Available: http://www.sciencedirect.com/science/article/B6W4J-4VNCC2D-1/2/b95c604ef6217fd370ca56a38306c21d

Epitropaki, O., \& Martin, R. (2004). Implicit leadership theories in applied settings: Factor structure, generalizability, and stability over time. Journal of Applied Psychology, 89(2), 293-310. http://dx.doi.org/10.1037/0021-9010.89.2.293

George, W. R. (1990). Internal marketing and organizaitonal behavior: A partnership in developing customer conscious employees at every level. Journal of Business Research, 1, 63-70.

Gjerald, O., \& Øgaard, T. (2008). Why should hospitality management focus more on the construct of basic assumptions? A review and research agenda. Scandinavian Journal of Hospitality and Tourism, 8(4), 294-316.

Gjerald, O., \& Øgaard, T. (2010a). Eliciting and analysing the basic assumptions of hospitality employees about guests, co-workers and competitors. International Journal of Hospitality Management, 29(3), 476-487. http://dx.doi.org/10.1016/j.ijhm.2009.11.003

Gjerald, O., \& Øgaard, T. (2010b). Exploring the measurement of basic assumptions about guests and co-workers in the hospitality industry. International Journal of Contemporary Hospitality Management, 22(6), 887-909. http://dx.doi.org/10.1108/09596111011063142

Gronroos, C. (2008). Service logic revisited: who creates value? And who co-creates? European Business Review, 20(4), 298 - 314.

Harris, S. G., \& Mossholder, K. W. (1996). The affective implications of perceived congruence with culture dimensions during organizational transformation. Journal of Management, 22(4), 527-547.

Hartline, M. D., \& Ferrell, O. C. (1996). The management of customer-contact service employees: An empirical investigation. Journal of Marketing, 60(4), 52-70.

Heslin, P. A., Latham, G. P., \& VandeWalle, D. (2005). The effect of implicit person theory on performance appraisals. Journal of Applied Psychology, 90(5), 842-856. http://dx.doi.org/10.1037/0021-9010.90.5.842

Hochschild, A. (1983). The managed heart: Commercialization of human feeling. Berkeley, CA: University of California Press.

Hochwälder, J. (1995). On stability of the structure of implicit personality theory over situations. Scandinavian Journal of Psychology, 36, 386-398.

Ingram, H. (1997). Performance management: processes, quality and teamworking. International Journal of Contemporary Hospitality Management, 9(7), 295-303.

Janoff-Bulman, R. (1989). Assumptive World and the stress of traumatic events: applications of the schema construct. Social Cognition, 7(2), 113-136.

Jaworski, B. J., \& Kohli, A. K. (1993). Market Orientation - Antecedents And Consequences. Journal of Marketing, 57(3), 53-70. 
Kaur, G., \& Gupta, M. C. (2010). A perusal of extant literature on market orientation - concern for its implementation. The Marketing Review, 10(1), 87-105.

Kluckhohn, C. (1951). Values and value orientation in the theory of action. In T. Parsons \& E. A. Shields (Eds.), Towards a general theory of action (pp. 388-433). Cambridge, MA: Harvard University Press.

Kohli, A. K., Jaworski, B. J., \& Kumar, A. (1993). Markor - A measure of Market Orientation. Journal of Marketing Research, 30(4), 467-477.

Koltko-Rivera, M. E. (2000). The Worldview Assessment Inventory (WAI): The development and preliminary validation of an instrument to assess world view components relevant to counseling and psychotherapy. New York University, New York.

Lashley, C. (2001). Is there any power in empowerment? In A. Roper \& Y. Guerrier (Eds.), A decade of hospitality management research: Tenth anniversary volume (pp. 56-78). Newbury: Threshold Press.

Lord, R. G., \& Brown, D. J. (2001). Leadership, values, and subordinate self-concepts. Leadership Quarterly, 12(2), $133-152$.

Lord, R. G., \& Brown, D. J. (2004). Leadership processes and follower self-identity. Mahwah, N.J.: Lawrence Erlbaum.

Lord, R. G., \& Emrich, C. G. (2000). Thinking outside the box by looking inside the box: Extending the cognitive revolution in leadership research. Leadership Quarterly, 11(4), 551-579.

Lord, R. G., \& Maher, K. J. (1993). Leadership and information processing: Linking perceptions and performance. London: Routledge.

Mikkelsen, E. G., \& Einarsen, S. (2002). Basic assumptions and symptoms of post-traumatic stress among victims of bullying at work. European Journal of Work and Organizational Psychology, 11(1), 87-111.

Morgan, N. A., Vorhies, D. W., \& Mason, C. H. (2009). Market orientation, marketing capabilities, and firm performance. Strategic Management Journal, 30(8), 909-920.

Moscovici, S. (2000). Social representations. Exploration in Social Pscyhology. Cambridge: Polity Press.

Nunnally, J. C. (1978). Psychometric theory (2nd ed.). New York: McGraw Hill.

Oliver, R. L., \& Anderson, E. (1995). Behavior- and outcome-based sales control systems: Evidence and consequences of pure-form and hybrid governance. Journal of Personal Selling \& Sales Management, 15(4), 1-15.

Pfeffer, J. (2005). Changing mental models: HR's most important task. Human Resource Management, 44(2), 123-128.

Philip, G., \& McKeown, I. (2004). Business transformation and organizational culture: The role of competency, IS and TQM. European Management Journal, 22(6), 624-636.

Pine, J., \& Gilmore, J. (1999). The experience economy: Work is theatre and every business a stage. Boston, Massachussets: Harvard Business School Press.

Reychav, I., \& Weisberg, J. (2009). Going beyond technology: Knowledge sharing as a tool for enhancing customer-oriented attitudes. International Journal of Information Management, 29(5), 353-361. http://dx.doi.org/10.1016/j.ijinfomgt.2008.11.005

Schein, E. (1985). How Culture Forms, Develops and Changes. In R. H. Kilmann, M. J. Saxton \& R. Serpa (Eds.), Gaining control of the corporate culture (pp. 17-43). San Francisco: Jossey-Bass

Schein, E. (2004). Organizational culture and leadership (3rd ed.). San Francisco: Jossey-Bass.

Schein, E. (2005). Organizational culture theory. In J. M. Shafritz, J. S. Ott \& Y. S. Jang (Eds.), Classics of organization theory (pp. 360-367). Belmont, CA: Thomson Wadsworth.

Silva, M., Moutinho, L., Coelho, A., \& Marques, A. (2009). Market orientation and performance: modelling a neural network. European Journal of Marketing, 43(3/4), 421-437.

Urry, J. (1990). The Tourist Gaze. London: Sage.

Van der Heijden, B. (2001). Age and assessments of professional expertise: The relationship between higher level employees' age and self-assessments or supervisor ratings of professional expertise. International Journal of Selection and Assessment, 9(4), 309-324. 
Vargo, S. L., \& Lusch, R. F. (2004). Evolving to a new dominant logic for marketing. Journal of Marketing, 68, $1-17$.

Vargo, S. L., \& Lusch, R. F. (2008). Why "service"? Journal of the Academy of Marketing Science, 36(1), $25-38$.

Wentzel, D., Henkel, S., \& Tomczak, T. (2010). Can I Live Up to That Ad? Impact of Implicit Theories of Ability on Service Employees' Responses to Advertising. Journal of Service Research, 13(2), 137-152.

Table 1. Hypotheses investigated in the study

\begin{tabular}{ll}
\hline N & Hypothesis \\
\hline H1a & Basic assumption about customer control is positively related to employee job performance. \\
H1b & Basic assumption about customer affect is negatively related to employee job performance. \\
H1c & Basic assumption about co-worker responsibility is positively related to employee job performance. \\
H1d & Basic assumption about co-worker competence is positively related to employee job performance. \\
H2a1 & Basic assumption about customer control is negatively related to intelligence generating behavior. \\
H2a2 & Basic assumption about customer control is negatively related to intelligence disseminating behavior. \\
H2a3 & Basic assumption about customer control is negatively related to responsiveness behavior. \\
H2b1 & Basic assumption about customer affect is positively related to intelligence generating behavior. \\
H2b2 & Basic assumption about customer affect is positively related to intelligence disseminating behavior. \\
H2b3 & Basic assumption about customer affect is positively related to responsiveness behavior. \\
H2c1 & Basic assumption about co-worker responsibility is positively related to intelligence generating behavior. \\
H2c2 & Basic assumption about co-worker responsibility is positively related to intelligence disseminating behavior. \\
H2c3 & Basic assumption about co-worker responsibility is positively related to responsiveness behavior. \\
H2d1 & Basic assumption about co-worker competence is positively related to intelligence generating behavior. \\
H2d2 & Basic assumption about co-worker competence is positively related to intelligence disseminating behavior. \\
H2d3 & Basic assumption about co-worker competence is positively related to responsiveness behavior.
\end{tabular}

Table 2. Means, standards deviations, factor analysis results, and reliabilities of the constructs

\begin{tabular}{|c|c|c|c|c|c|c|}
\hline & $\begin{array}{l}\mathrm{N} \text { of } \\
\text { items }\end{array}$ & $\begin{array}{l}\text { Scale } \\
\text { Mean } \\
(S D)\end{array}$ & $\begin{array}{l}\text { Variance } \\
\text { extracted } \\
\text { first factor } \\
(\%)\end{array}$ & $\begin{array}{l}\text { Range of } \\
\text { factor } \\
\text { loadings }\end{array}$ & $\begin{array}{l}\text { Range of } \\
\text { communalities }\end{array}$ & $\begin{array}{l}\text { Coefficient } \\
\text { alpha }\end{array}$ \\
\hline $\begin{array}{l}\text { Basic assumption } \\
\text { about customer } \\
\text { control }\end{array}$ & 11 & $\begin{array}{l}3.3 \\
(1.09)\end{array}$ & 41 & $.54-.74$ & $.33-.55$ & .85 \\
\hline $\begin{array}{l}\text { Basic assumption } \\
\text { about customer affect }\end{array}$ & 6 & $\begin{array}{l}5.8 \\
(0.73)\end{array}$ & 39 & $.60-.76$ & $.46-.70$ & .68 \\
\hline $\begin{array}{l}\text { Basic assumption } \\
\text { about co-worker } \\
\text { responsibility }\end{array}$ & 5 & $\begin{array}{l}6.3 \\
(0.65)\end{array}$ & 45 & $.51-.76$ & $.52-.79$ & .69 \\
\hline $\begin{array}{l}\text { Basic assumption } \\
\text { about co-worker } \\
\text { competence }\end{array}$ & 9 & $\begin{array}{l}6.2 \\
(0.68)\end{array}$ & 42 & $.50-.70$ & $.38-.58$ & .82 \\
\hline $\begin{array}{l}\text { Intelligence } \\
\text { generation }\end{array}$ & 10 & $\begin{array}{l}4.9 \\
(.96)\end{array}$ & 31 & $.41-.63$ & $.17-.48$ & .55 \\
\hline $\begin{array}{l}\text { Intelligence } \\
\text { dissemination }\end{array}$ & 8 & $\begin{array}{l}4.9 \\
(1.22)\end{array}$ & 52 & $.53-.78$ & $.28-.67$ & .74 \\
\hline Responsiveness & 14 & $\begin{array}{l}5.3 \\
(.93)\end{array}$ & 36 & $.50-.72$ & $.25-.52$ & .77 \\
\hline $\begin{array}{l}\text { Subjective job } \\
\text { performance }\end{array}$ & 2 & $\begin{array}{l}5.6 \\
(1.14)\end{array}$ & 79 & $.88-.89$ & $.78-.79$ & .74 \\
\hline
\end{tabular}


Table 3. Standardized factor loadings for the four dimensions of the 31-item basic assumptions scale

Questionnaire items

Basic assumption about customer control

It is important in this job to know what kind of day you will have.

We prefer guests who behave the way we expect them to.

We do not let our guests' demands keep us from doing things we scheduled for the day.

Guests' complains are their way of demonstrating power.

Rules and practices that have been around for many years should

determine what would happen to a complaining guest.

In my work with guests, I prefer predictability.

Distance from the guest gives me safety.

In this job, strict rules and routines are necessary to make guest

interaction as predictable as possible.

In this organisation, we are good at setting limits for how much the

guests can demand.

We take control when interacting with guests.

In this organization, we sometimes give less priority to the flexibility of products offered to achieve more control over the service interaction.

Basic assumption about customer affect

Putting your emotions on display makes you feel closer to the guest.

It is important in my work to feel that I work for someone.

In this occupation, you develop a strong sense of connection to "the other".

Being open minded is important in order to treat everyone fairly.

Whenever something good happens, I feel we have earned it.

Some guests are just easy to like.

Basic assumption about co-worker responsibility

Being self-reliant is an advantage in this job.

Resourceful and self-sufficient co-workers are highly appreciated in this organization.

A good co-worker is someone who acknowledges his/her responsibility to his/her colleagues.

Good co-workers are willing to deal with issues on their colleagues' behalf.

It is important in this job to be able to trust your co-workers.

Basic assumption about co-worker competence

Being able to take criticism is an important part of this job.

Efficient task-solving is rewarded in our organization.

A competent co-worker knows his/her job better than a "training manual".

Good co-workers can improvise.

In this job, you depend on having good dialogue with your colleagues.

Good co-workers are very open to alternative solutions.

Team players are the best co-workers.

A good co-worker is someone who contributes largely to teamwork.

It is crucial to be able to communicate freely with your colleagues in order to succeed in this job.

$\begin{array}{cccc}\text { Factor loadings } & & \\ 1 & 2 & 3 & 4\end{array}$

.558

.608

.575

.718

.685

.660

.646

.580

.640

.614

.635
.697

.722

.654

.457

.569

.383 
Table 4. Correlations among all scales $(N=241)$

\begin{tabular}{lllllllll}
\hline Subscales & $\mathbf{1}$ & $\mathbf{2}$ & $\mathbf{3}$ & $\mathbf{4}$ & $\mathbf{5}$ & $\mathbf{6}$ & $\mathbf{7}$ & $\mathbf{8}$ \\
\hline 1.Customer control & 1 & & & & & & \\
2.Customer affect & -0.08 & 1 & & & & & \\
3.Co-worker responsibility & -0.07 & $0.37^{* *}$ & 1 & & & & \\
4.Co-worker competence & -0.10 & $0.39^{* *}$ & $0.46^{* *}$ & 1 & & & \\
5.Intelligence generation & $-0.15^{* *}$ & $0.20^{* *}$ & $0.18^{* *}$ & $0.27^{* *}$ & 1 & & \\
6.Intelligence dissemination & -0.09 & $0.17^{*}$ & $0.18^{* *}$ & $0.26^{* *}$ & $0.53^{* *}$ & 1 & & \\
7.Responsiveness & $-0.27^{* *}$ & $0.24^{* *}$ & $0.24^{* *}$ & $0.28^{* *}$ & $0.60^{* *}$ & $0.59^{* *}$ & 1 & \\
8.Subjective job performance & $0.15^{*}$ & $0.16^{*}$ & $0.19^{* *}$ & $0.27^{* *}$ & 0.05 & $0.16^{*}$ & $0.17^{*}$ & 1 \\
\hline
\end{tabular}

Note: ${ }^{*} p<.05, * * p<.01$

Table 5. Summary of regression analysis for variables predicting subjective employee job performance $(N=241)$

\begin{tabular}{llll}
\hline Variables & $B$ & $S E B$ & \multicolumn{1}{c}{$\beta$} \\
\hline Basic assumption about customer control & .185 & .063 & $.177^{*}$ \\
Basic assumption about customer affect & .073 & .110 & .048 \\
Basic assumption about co-worker responsibility & .165 & .137 & .091 \\
Basic assumption about co-worker competence & .373 & .124 & $.227^{* *}$ \\
\hline & $R$ & $R^{2}$ & Adjusted $R^{2}$ \\
& .336 & .113 & .097 \\
\hline
\end{tabular}

Note: ${ }^{*} p<\overline{.01, * * p<.005}$

Table 6. Summary of regression analysis for basic assumptions scales predicting market-oriented behaviors $(N=241)$

\begin{tabular}{llll}
\hline Variables & $\begin{array}{l}\text { Intelligence } \\
\text { generation }\end{array}$ & $\begin{array}{l}\text { Intelligence } \\
\text { dissemination }\end{array}$ & Responsiveness \\
\hline & $\beta$ & $\beta$ & $\mathrm{B}$ \\
\hline Basic assumption about customer control & $-.12^{*}$ & - & $-.24^{*}$ \\
Basic assumption about customer affect & - & - & $.12^{* *}$ \\
Basic assumption about co-worker responsibility & - & - & - \\
Basic assumption about co-worker competence & $.20^{*}$ & $.20^{*}$ & $.17^{*}$ \\
\hline & $R^{2}=.10$ & $R^{2}=.08$ & $R^{2}=.17$ \\
\hline
\end{tabular}

Note: ${ }^{*} p \leq .05, * * p \leq .10$

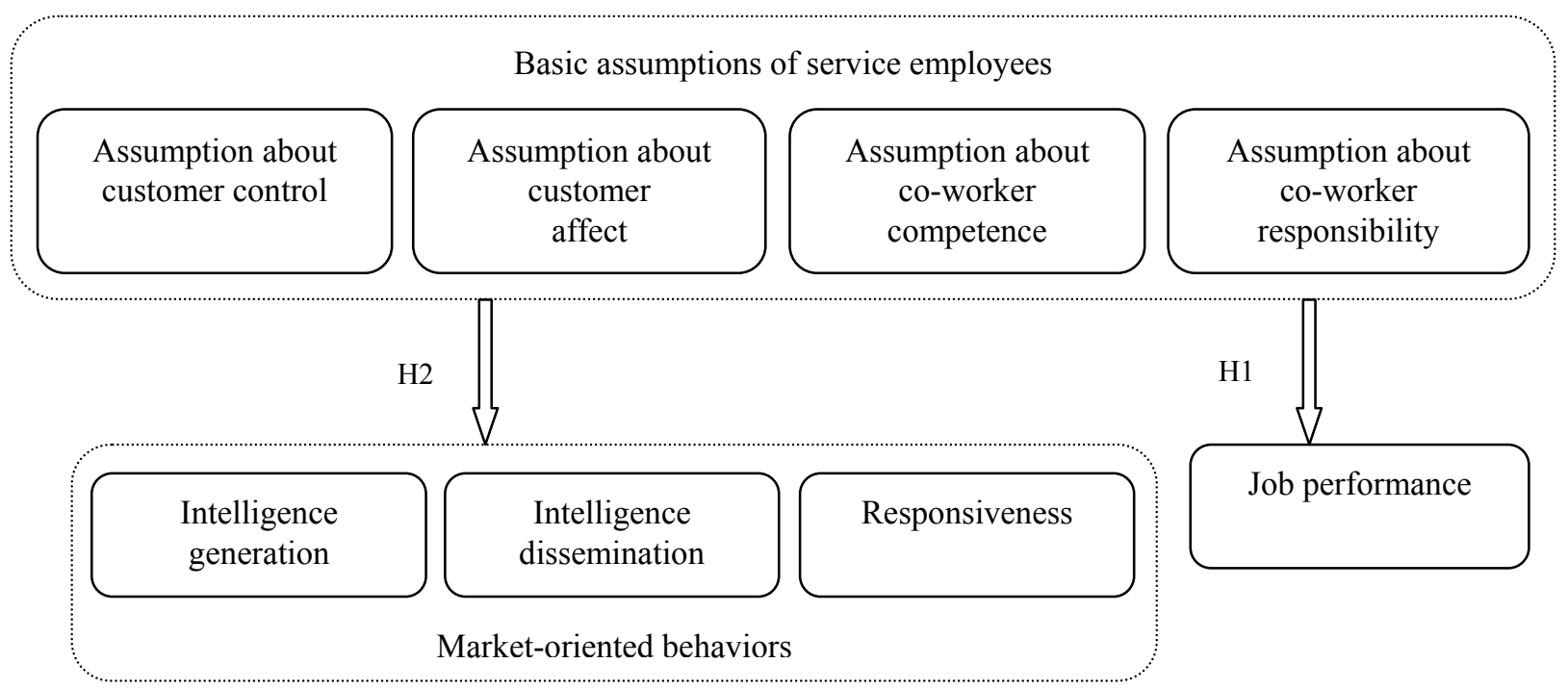

Figure 1. The hypothesized relationships among basic assumptions, employee job performance, and market orientation behaviors 